\section{A COBERTURA MIDIÁTICA SOBRE O FUTSAL MASCULINO NO BRASIL: PERSPECTIVA DOS ATLETAS DA SELEÇÃO BRASILEIRA PRINCIPAL}

\author{
MEDIA COVERAGE ON BRAZILIAN MEN'S FUTSAL: NATIONAL SENIOR TEAM \\ PLAYERS' PERSPECTIVE
}

\begin{abstract}
LA COBERTURA MEDIÁTICA SOBRE EL FUTSAL MASCULINO EN BRASIL: PERSPECTIVA DE LOS ATLETAS DE LA SELECCIÓN PRINCIPAL
\end{abstract}

Renato Francisco Rodrigues Marques*, Wanderley Marchi Junior**

\section{Palavras chave:}

Meios de

comunicação.

Futsal.

Esportes de elite.

Sociologia.
Resumo: O Brasil se destaca pelo número de praticantes e conquistas internacionais no futsal. Este esporte encontra-se em processo de consolidação da profissionalização de suas práticas no país. Consequentemente, a mídia torna-se fundamental para a atração de consumidores e investidores. 0 objetivo deste estudo foi investigar a perspectiva de jogadores brasileiros de elite de futsal relativa à cobertura midiática sobre este esporte no Brasil. Foram realizadas entrevistas com 21 jogadores da seleção brasileira masculina principal de futsal. Após análise temática, as categorias analíticas foram discutidas com base na Teoria dos Campos de Pierre Bourdieu. Concluiu-se que, segundo os jogadores, o futsal ocupa um espaço desprestigiado na mídia esportiva, o que dificulta a atração de investimentos e desenvolvimento de carreiras. Os jogadores propõem ações ortodoxas que tentam se adaptar às normas do campo, de modo a alcançarem capitais econômicos e simbólicos que melhorem suas condições de trabalho e posição na estrutura social.
Keywords:

Media.

Futsal.

Elite sports.

Sociology.
Abstract: Brazil has many futsal practitioners and is the main winner of world championships; professionalism is increasing in the country. Thus, the media play a key role in attracting consumers and investors. This study investigates the perspective of Brazilian elite male players on the media coverage. Semi-structured interviews were conducted with 21 national team members. After players' discourses underwent thematic analysis, analytic categories were subjected to Pierre Bourdieu's Theory of Fields. According to players, futsal is discredited in sports media coverage, hampering the attraction of investors and career development. Players propose orthodox actions to adapt to the rules of the field in order to gain economic and symbolic capitals that may improve their work conditions and social status.

Palabras clave: Medios.

Futsal.

Deportes de élite. Sociología
Resumen: Brasil se destaca por el número de practicantes y por las conquistas internacionales en futsal, y la profesionalización de sus prácticas se consolida en el país. Los medios son fundamentales para atraer a consumidores e inversores, y este estudio investigó la perspectiva de jugadores de élite sobre la cobertura mediática. Se realizaron entrevistas con 21 jugadores de la selección masculina principal. Las categorías analíticas fueron discutidas con base en la Teoría de los Campos de Pierre Bourdieu. Según los jugadores, el futsal tiene poco prestigio en la prensa deportiva, lo que dificulta inversiones y desarrollar carreras. Los jugadores proponen acciones ortodoxas para adaptarse a las normas del campo y alcanzar capitales económicos y simbólicos que mejoren sus condiciones de trabajo y su posición social...
*Universidade de São Paulo. São Paulo, SP, Brasil. E-mail: renatomarques@usp.br

**Universidade Federal do Paraná Curitiba, PR, Brasil. E-mail: marchijp@ufpr.br

Recebido em: 04-09-2018 Aprovado em: 10-12-2018 Publicado em: 22-04-2019

DOI: https://doi.org/10.22456/1982-8918.75560 (c) (1) (8) Licence 


\section{INTRODUÇÃO}

O futsal é um esporte praticado nos cinco continentes, ganhando importância em nível mundial nas últimas décadas (SANTANA; RIBEIRO, 2010; MARQUES et al., 2013; BERDEJO DEL FRESNO, 2014; MOORE et al., 2014). No Brasil, o futsal é o $4^{\circ}$ esporte mais praticado pelo público em geral, o $1^{\circ}$ em número de praticantes adolescentes no lazer (MINISTÉRIO DO ESPORTE, 2015) e o mais praticado em escolas (VOSER; GIUSTI, 2015). O Brasil apresenta uma hegemonia de títulos mundiais na categoria principal, sendo heptacampeão masculino e hexacampeão feminino (MARQUES; MARCHI JUNIOR, 2017).

Atualmente, o futsal encontra-se em processo de consolidação da profissionalização de suas práticas no Brasil, sendo uma carreira que pode ser profícua para homens (MARQUES; MARCHI JUNIOR, 2017), mas pouco ainda para mulheres (ALTMANN; REIS, 2013). Por isso, assim como outros esportes (MARCHI JUNIOR, 2004; MARQUES; GUTIERREZ, 2014), demanda mudanças em práticas cultural e historicamente estabelecidas, para melhoria de suas condições de comércio e trabalho.

Os interesses e a lógica comercial do esporte baseiam-se na proximidade entre espectadores/consumidores e empresas que desejam vender seus produtos a esse público (HOWE, 2004). Os veículos midiáticos são essenciais para tal aproximação (ROWE; GILMOUR, 2010) e legitimação simbólica e social do esporte (SANFELICE, 2010), ao mesmo tempo em que precisam dele como notícia atrativa aos espectadores, que também assumem um papel de consumidores neste processo (COAKLEY, 2017). Neste cenário, embora contribua para a divulgação mercadológica do esporte, a mídia também o utiliza como meio de disseminação ideológica (BOURDIEU, 1997).

Como outros campos que apresentam características mercadológicas, o esporte profissional depende diretamente de sua divulgação (PIRES, 2006), não apenas como produto, mas como gerador de novos produtos, sendo essa relação um fator determinante sobre carreiras de atletas (COAKLEY, 2017). Estar presente na agenda dos principais meios de comunicação é um desejo para qualquer forma de manifestação esportiva que procure sucesso no campo comercial (SHERWOOD; NICHOLSON; MARJORIBANKS, 2017). Ser conhecido, consumido e estabelecer laços com o grande público é essencial para o sucesso mercadológico de um esporte e seus atletas profissionais (HAHN; CUMMINS, 2017).

Neste processo, disputas por poder dificultam ou facilitam ações de divulgação e comercialização do espetáculo esportivo (BOURDIEU, 1997; BOURDIEU; DAUNCEY; HARE, 1998). Compreendê-las é um requisito para melhor estruturar os meios de organização e disseminação da prática e consumo (COAKLEY, 2017). Porém, há uma lacuna na literatura, e pouco conhecimento sobre as relações do futsal com a mídia, assim como de estudos socioculturais sobre esse esporte (MOORE et al., 2014; CAREGNATO et al., 2015).

Considerando este cenário, o objetivo deste estudo foi investigar e promover uma reflexão sobre a perspectiva de jogadores brasileiros de elite de futsal a respeito da cobertura midiática realizada sobre este esporte no Brasil.

Este trabalho justifica-se ao oferecer uma reflexão a partir do ponto de vista dos protagonistas do espetáculo esportivo, os próprios atletas, dando-lhes voz sobre suas percepções relativas ao modo como são retratados e a influência da cobertura midiática sobre 0 
desenvolvimento do futsal e, em consequência, de suas carreiras profissionais. Tais informações, além de contribuírem para uma melhor compreensão sobre o universo midiático relacionado ao futsal, ainda oferecem subsídios teóricos que podem vir a nortear a ação de outros agentes do campo esportivo, como dirigentes esportivos, jornalistas, editores e demais profissionais da mídia especializada, além de estudos posteriores sobre esta temática: a) elaboração de políticas de organização do futsal que melhorem sua massificação, espetacularização e comercialização; b) reflexão sobre a cobertura midiática sobre o futsal; c) reflexão sobre os modos de organização do futsal e seu potencial para tornar-se interessante tanto para a mídia, quanto para investidores e público; d) organização e melhoria de processos administrativos e sociais ligados às condições de trabalho de jogadores de elite de futsal no Brasil.

Para subsidiar tal investigação, este estudo utilizou algumas categorias da sociologia reflexiva de Pierre Bourdieu e sua Teoria dos Campos (BOURDIEU, 1993, 1998a, 2013; BOURDIEU; WACQUANT, 1992). Tal opção se deu devido a esse referencial teórico oferecer subsídios para interpretação, reflexão e discussão sobre os processos de estruturação e interação entre os campos esportivo e midiático, além dos modos de intervenção de seus agentes sociais (SANFELICE, 2010). Bourdieu propõe categorias que sustentam uma análise crítica e reflexiva sobre a cobertura midiático-esportiva, no sentido de elucidar, entre outras possibilidades, questões ligadas às relações ocultas de dominação e suas influências sobre as disposições para ação. Além disso, o trabalho deste autor é comumente utilizado como referencial teórico para estudos socioculturais sobre o esporte (CUSHION; KITCHEN, 2011), especificamente em questões relativas a disputas por poder nos campos esportivo (MARCHI JUNIOR, 2004) e jornalístico (HESMONDHALGH, 2006), além da relação entre ambos (MARQUES et al. 2015).

\section{A TEORIA DOS CAMPOS DE PIERRE BOURDIEU: CONTRIBUIÇÕES PARA ESTUDOS SOBRE OS CAMPOS ESPORTIVO E MIDIÁTICO}

Como fundamento de análise sociológica para este trabalho tem-se a Sociologia Reflexiva de Pierre Bourdieu e sua Teoria dos Campos. Este autor desenvolveu suas contribuições sociológicas apoiadas na denúncia do jogo de dominação oriundo da distribuição e acesso desigual de bens e disputas entre grupos em diversos campos da sociedade (BOURDIEU, 1993; 1998a; 2013; BOURDIEU; WACQUANT, 1992).

Um campo é parcialmente autônomo em relação à sociedade como um todo, e se conforma por suas normas e objetos em disputa entre grupos com interesses específicos (BOURDIEU, 1989). Cada campo ou subcampo (espaços que respeitam as normas do campo, mas também apresentam particularidades e parcial autonomia dentro dele) baseia-se em uma estrutura social, arquitetada pelas posições ocupadas pelos grupos e agentes (BOURDIEU, 2013), que lutam contra, ou pelo acesso à violência simbólica (a orientação sobre a conservação ou mudanças das formas de distribuição de poder) com base no reconhecimento relativo à sua posse de capitais (BOURDIEU, 1993).

Têm-se quatro formas essenciais de capitais, passíveis de conversão entre si (BOURDIEU, 1986; 1989; 1998a): econômico (acesso e posse de dinheiro), social (círculo social e relações interpessoais), cultural (conhecimento adquirido e suas formas de demonstração e certificação, manifestando-se de modo incorporado, institucionalizado ou objetivado) e simbólico (qualquer forma de capital que em contextos particulares é valorizado). 
Outro ponto fundamental da obra de Bourdieu é a noção de habitus, um sistema de disposições adquirido por aprendizagem explícita ou implícita, que funciona como uma estrutura estruturada e estruturante de formas de percepção e ação no mundo social, norteando as práticas de forma muitas vezes imperceptível pelo sujeito (BOURDIEU, 1993; 1998a). Nos campos, cada grupo e agentes apresentam habitus próprios, determinados por seus capitais e posição na estrutura social (BOURDIEU, 1998a).

As disputas por poder nos campos criam uma doxa, o ponto de vista dos dominantes, que se apresenta e se impõe como ponto de vista universal, forma de orquestração dos habitus (BOURDIEU, 1998a). A aqueles agentes que monopolizam o capital e violência simbólica, interessa a conservação e manutenção da estrutura social - ortodoxia -, enquanto os que possuem menos acesso ao capital tendem a estratégias de subversão - heterodoxia (BOURDIEU, 1993).

Dentre diversos campos sociais estudados por Pierre Bourdieu, pode-se citar 0 esportivo (BOURDIEU, 1988; 1993; 2013) e o jornalístico (BOURDIEU, 1997). No esportivo, Bourdieu valeu-se de uma análise sócio-histórica como forma de mapear e consolidar um espaço social das práticas esportivas, baseado em mecanismos de distinções sociais por vias simbólicas (BOURDIEU, 1988; 1993; 2013). No jornalístico, denunciou a submissão dos agentes à lógica comercial da notícia, além do habitus ortodoxo como forma de manter-se engajado nas principais posições deste espaço (BOURDIEU, 1997). Neste presente trabalho, consideramos o futsal como um subcampo do campo esportivo, e o subcampo midiático-esportivo como parte do campo jornalístico.

Embora não tenha estudado especificamente o esporte da sociedade globalizada do século XXI, Bourdieu oferece uma série de subsídios teóricos que possibilitam jornadas sociológicas sobre o esporte contemporâneo (MARCHI JUNIOR, 2004; 2015; GIULIANOTTI, 2005; CUSHION; KITCHEN, 2011; MARQUES, 2015a; 2015b). Este autor sugere que o esporte de alto rendimento, assim como qualquer outra forma de manifestação esportiva, sofre influência e estrutura-se por relações de poder próprias (BOURDIEU, 1993), como a ação de dirigentes que interferem sobre os meios e formas de atuação de atletas e público consumidor (BOURDIEU; DAUNCEY; HARE, 1998), e da cobertura midiática pelos veículos de comunicação e jornalistas, como meio de fortalecimento do nacionalismo e demais interesses do estado e mercado (BOURDIEU, 1997).

\section{MÉTODOS}

Este estudo faz parte de um projeto maior de pesquisa qualitativa, baseado em entrevistas semiestruturadas com jogadores da seleção brasileira masculina principal de futsal, com o objetivo de investigar o desenvolvimento da carreira de atletas brasileiros de futsal masculino de alto rendimento.

A abordagem sobre a cobertura midiática proposta neste estudo se dá em relação a sua influência sobre o desenvolvimento da carreira profissional dos atletas, além de suas condições de trabalho. Para isso, partiu-se do pressuposto de que a mídia é um componente fundamental, que não pode ser desvinculado do esporte de alto rendimento contemporâneo (COAKLEY, 2017; WENNER, 2018), ou seja, parte da composição social que estrutura os modos de ação dos agentes do campo esportivo (BOURDIEU, 1997; BOURDIEU; DAUNCEY; HARE, 1998). 
Este projeto obteve aprovação do Comitê de Ética em Pesquisa da universidade sede do primeiro autor (CAAE: 49580815.2.0000.5659).

\subsection{PARTICIPANTES}

Os critérios de inclusão para participantes nesta pesquisa foram: a) ter disputado pelo menos uma partida na Liga Nacional de Futsal (LNF) masculina, principal competição de futsal no Brasil, entre os anos de 2014 e 2016 (mesmo período de realização das entrevistas); e b) ter sido convocado e ter jogado pelo menos uma partida pela seleção brasileira masculina principal. Foram contatados cinco gestores de clubes de futsal participantes da LNF para auxiliar no recrutamento dos jogadores. Tais colaboradores forneceram possíveis datas de entrevistas e locais adequados, garantindo que os procedimentos não interfeririam nas atividades de treinamento e/ou competição.

Foram entrevistados 21 jogadores. Os atletas foram designados aleatoriamente com um número (P1 a P21) para proteger suas identidades. A Tabela 1 fornece uma perspectiva geral da carreira dos entrevistados:

Tabela 1 - Características da carreira dos jogadores nas datas das entrevistas

\begin{tabular}{|c|c|c|c|c|}
\hline Participantes & Idade & $\begin{array}{c}\text { Idade quando recebeu } \\
\text { primeiro salário como } \\
\text { jogador de futsal de } \\
\text { elite }\end{array}$ & $\begin{array}{l}\text { Idade quando foi } \\
\text { convocado pela primeira } \\
\text { vez para a seleção } \\
\text { brasileira principal }\end{array}$ & $\begin{array}{c}\text { Número de anos de } \\
\text { experiência como } \\
\text { jogador de futsal de } \\
\text { elite }\end{array}$ \\
\hline $\mathrm{P} 1$ & 41 & 20 & 20 & 21 \\
\hline $\mathrm{P} 2$ & 40 & 18 & 21 & 22 \\
\hline P3 & 38 & 19 & 25 & 19 \\
\hline P4 & 30 & 17 & 27 & 13 \\
\hline P5 & 30 & 18 & 24 & 12 \\
\hline P6 & 24 & 16 & 19 & 8 \\
\hline P7 & 31 & 16 & 28 & 15 \\
\hline P8 & 30 & 16 & 27 & 14 \\
\hline P9 & 32 & 19 & 22 & 13 \\
\hline P10 & 24 & 17 & 20 & 7 \\
\hline P11 & 27 & 17 & 18 & 10 \\
\hline P12 & 36 & 16 & 19 & 20 \\
\hline P13 & 30 & 21 & 18 & 9 \\
\hline P14 & 32 & 21 & 25 & 11 \\
\hline P15 & 30 & 19 & 18 & 11 \\
\hline P16 & 32 & 18 & 20 & 14 \\
\hline P17 & 30 & 20 & 28 & 10 \\
\hline P18 & 25 & 16 & 22 & 9 \\
\hline P19 & 40 & 23 & 31 & 17 \\
\hline P20 & 32 & 16 & 18 & 16 \\
\hline P21 & 30 & 18 & 22 & 12 \\
\hline $\begin{array}{c}\text { Média } \pm \\
\text { Desvio padrão }\end{array}$ & $31,6 \pm 4,9$ & $18,1 \pm 2,0$ & $22,5 \pm 4,0$ & $13,5 \pm 4,3$ \\
\hline
\end{tabular}




\subsection{PRODUÇÃO E ANÁLISE DE DADOS}

A produção de dados envolveu uma entrevista semiestruturada com cada jogador, com duração entre 30 e 60 minutos. Cada entrevista foi registrada com um gravador digital e transcrita literalmente.

Utilizou-se um roteiro para guiar as entrevistas com perguntas sobre as perspectivas dos atletas, lembranças e pontos de vista pessoais sobre suas próprias experiências e sobre os agentes sociais que influenciaram suas carreiras esportivas significativamente no alto rendimento. $\mathrm{O}$ guia de entrevista consistiu de três seções: a) informações pessoais; b) carreira profissional no futsal; c) agentes e grupos sociais que influenciam o desenvolvimento da carreira profissional no esporte. A cobertura midiática foi abordada como parte da seção 'c', tendo como pergunta norteadora para este tópico "Fale sobre a relação entre a mídia e o futsal".

Para a análise dos dados, seguiu-se o procedimento de análise temática (BRAUN; CLARKE, 2006). Na familiarização com os dados, foi adotada uma análise indutiva, "[...] um processo de codificação dos dados sem tentar encaixá-lo em um quadro de codificação preexistente, ou os preconceitos analíticos do pesquisador" (BRAUN; CLARKE, 2006, p.83). Durante este processo, temas iniciais foram identificados nas transcrições das entrevistas.

Em uma etapa seguinte, foram considerados os dados do tema "abordagens midiáticas sobre o futsal" e adotou-se uma análise teórica, que "[...] tende a ser impulsionada pelo interesse teórico ou analítico do pesquisador na área, sendo assim mais explicitamente orientada pelo analista" (BRAUN; CLARKE, 2006, p.84), pautada na Sociologia Reflexiva de Pierre Bourdieu. Isto levou à identificação de dois temas e suas respectivas categorias analíticas:

Tema 1: Processos de cobertura midiática sobre o futsal: a posição deste esporte no subcampo midiático-esportivo - Categorias: a) Descrição de processo de cobertura midiática; b) Avaliação sobre a cobertura midiática; c) Implicações da cobertura midiática.

Tema 2: Reflexões para a melhoria da cobertura midiática sobre o futsal: habitus dos jogadores e estratégias para acúmulo de capitais - Categorias: a) Implicações da cobertura midiática sobre a carreira dos atletas; b) Sugestões de melhorias da cobertura midiática.

\section{RESULTADOS E DISCUSSÃO}

Bourdieu e Wacquant (1992) sugerem alguns passos metodológicos para pesquisa em sociologia reflexiva: primeiro, mapear a estrutura social objetiva do campo, descrevendo seus agentes, grupos (e suas posições) e capitais; segundo, analisar o habitus de agentes e grupos, bem como as relações de poder entre eles.

Com base no discurso e perspectiva dos jogadores, o primeiro tema, "Processos de cobertura midiática sobre o futsal: a posição deste esporte no subcampo midiático-esportivo", consiste em uma descrição e análise da posição do futsal na estrutura objetiva do subcampo midiático-esportivo no Brasil, além da atuação dos veículos de comunicação no subcampo do futsal brasileiro. O segundo tema, "Reflexões para a melhoria da cobertura midiática sobre 0 futsal: habitus dos jogadores e estratégias para acúmulo de capitais", considera a posição dos jogadores no subcampo do futsal, seus habitus e capitais, e consiste em uma reflexão sobre 
as relações entre intervenções midiáticas e o desenvolvimento econômico e profissional do esporte, a partir da perspectiva e modos de ação dos atletas.

Para cada tema, discursos representativos foram incluídos, assim como a discussão com base na obra de Pierre Bourdieu e literatura da área.

\subsection{PROCESSOS DE COBERTURA MIDIÁTICA SOBRE O FUTSAL: A POSIÇÃO DESTE ESPORTE NO SUBCAMPO MIDIÁTICO-ESPORTIVO}

Alguns jogadores apontam que, embora a cobertura midiática sobre o futsal no Brasil ainda seja pouco abrangente, há certa melhoria em relação a períodos anteriores. Porém, devido a uma oferta ainda restrita de informação, é preciso predisposição do espectador/ consumidor para procurar informações ou transmissões de eventos.

\section{Melhorou bastante [cobertura midiática sobre o futsal]. Há vários jogos na televisão, o que não era tão comum. Campeonatos estaduais não passavam antes [na televisão], era só Liga Nacional, agora o [campeonato] Paulista é transmitido. Tem também campeonatos importantes, como 0 Gaúcho, com apenas algumas transmissões em televisão local (P4). \\ O espaço do futsal na mídia é pequeno. Em sites mais famosos, como SporTV ou ESPN, é difícil encontrar informações. $O$ interessado tem que procurar (P10).}

Devido a tais dificuldades para sua divulgação, o futsal ocuparia uma posição desprestigiada, sendo um "novo agente" (BOURDIEU, 1993) neste subcampo midiáticoesportivo, sem acesso pleno aos capitais em disputa (prestígio nos veículos de comunicação), assim como o reconhecimento simbólico de sua importância.

Percebe-se uma atitude crítica de jogadores frente a esta posição pois, embora valorizem certo aumento da cobertura midiática, demonstram insatisfação quanto aos conteúdos e processos de divulgação do futsal pela mídia.

A mídia poderia ser mais presente no dia a dia do futsal (P3).

[...] aqui [no Brasil], tu vais ao site da Confederação, não tem [boas informações], só tem os resultados. Então eu acho que [...] falta no Brasil, pra melhorar, entendeu, essa parte [cobertura midiática] (P18).

Foram também descritas diferenças entre o tipo e volume da cobertura midiática sobre o futsal entre diferentes regiões do país. Devido à maioria das equipes de futsal masculino da categoria principal no Brasil se localizar em cidades no interior dos estados (das 17 equipes da LNF 2017, apenas duas (11,7\%) tiveram sede em capitais - S.C. Corinthians Paulista, em São Paulo/SP, e Minas Tênis Clube, em Belo Horizonte/MG (LNF, 2017), enquanto que das 19 equipes da LNF 2018, somente três (15,7\%) apresentavam esta condição - S.C. Corinthians Paulista, em São Paulo/SP, Minas Tênis Clube, em Belo Horizonte/MG, Shouse Futsal, em Belém/PA (LNF, 2018)), a cobertura midiática seria principalmente direcionada a atrair espectadores em âmbito municipal e regional, privilegiando o interesse do público específico de cada equipe.

Eu não sei se isso ocorre pela falta de equipes no Rio de Janeiro/RJ, São Paulo/ $\mathrm{SP}, \mathrm{Curitiba/PR}$, nos grandes centros (P6).

Lá em Cascavel/PR [...] todo dia tinha uma [emissora de] televisão fazendo uma matéria do clube, tratando do próximo jogo (P8). 
Em Orlândia/SP e região, a divulgação é muito boa. No interior, o futsal é mais divulgado e valorizado (P10).

Devido a tal cenário, a cobertura midiática seria intensificada em esfera regional, limitando as possibilidades de acesso e consumo do futsal por parte do público de cidades que não hospedam equipes. Esse tipo de cobertura local fortalece o vínculo emocional e de representatividade social com grupos específicos, intensificando a sensação de pertencimento à comunidade (DAUNCEY; HARE, 2014). Assim, a concentração das equipes de futsal em cidades menores pode funcionar como um fator de fortalecimento dos laços entre os torcedores, e destes com a equipe da cidade, em um movimento similar ao apontado por Bourdieu (1997, p.123-124) em relação à transmissão dos Jogos Olímpicos por televisões em âmbito nacional: "[...] cada televisão nacional dá tanto mais espaço a um atleta ou a uma prática esportiva quanto mais eles forem capazes de satisfazer o orgulho nacional ou nacionalista". Esta forma de divulgação serve de reforço ou reprodução de uma lógica de pertencimento e identificação, estabelecendo e valorizando o próprio habitus e traços culturais coletivos (BOURDIEU, 2013), embora em algumas vezes o vínculo de equipes na mesma cidade seja curto e passageiro, devido a iniciativas pontuais de empresas/patrocinadoras ou ações de prefeituras.

Essa lógica de manifestação do sentimento coletivo e de representatividade pode ser mais difícil de ser realizada em grandes capitais, devido ao volume populacional e maior diversidade de habitus coletivos, além de concorrência entre diversas modalidades esportivas pela atenção de torcedores e consumidores (VIGARELLO, 2005). Nas grandes cidades que não contam com equipes de alto rendimento de futsal, esta modalidade esportiva acaba sendo mais um produto esportivo dentre inúmeros outros, que talvez tenham maior capital simbólico no subcampo midiático-esportivo.

Em contrapartida a este cenário, alguns entrevistados consideram o futsal com elevado potencial mercadológico e de espetacularização, porém, sem as devidas atenção e exploração por parte da mídia.

É um esporte legal, bom de ver, mais atrativo até que o futebol, porque em um minuto você pode virar um jogo (P20).

[...] o futsal, em termos de emoção, qualidade, não está atrás do basquete nem do vôlei. E olha a mídia que o vôlei tem. Exposição muito grande, patrocínio. Como eu falei, vôlei e basquete têm patrocínio de tudo. Então, por que o futsal não pode ser tão grande quanto? Eu acho que a mídia poderia [melhorar], sei lá, não faltam craques, tem muitos jogadores craques aqui (P6).

Eles apontam que, embora o futsal tivesse um bom potencial de espetacularização, e até de entretenimento, o público em geral pouco o consome, não conhecendo quem são seus principais agentes nem notícias sobre os bastidores. Neste cenário, despertar o interesse sobre uma modalidade esportiva seria um desafio para os veículos de comunicação (SANFELICE, 2010).

Para os jogadores, seria importante a transmissão de mais jogos e cobertura de temas variados, como reportagens sobre a carreira e vida pessoal de atletas e ex-atletas, além de menções em programas de debates esportivos. Informações suplementares, como rotina de atletas, vida pessoal e entrevistas são pouco ofertadas no futsal brasileiro, o que causa certo distanciamento do público espectador e dificulta a formação de vínculos de consumo e de apreciação com 0 esporte. Estas ferramentas são fundamentais para 0 aumento da 
cobertura midiática sobre o esporte (SHERWOOD; NICHOLSON; MARJORIEBANKS, 2017), além de contribuírem para o fortalecimento da perspectiva de entretenimento, sendo este um componente importante do discurso midiático-esportivo (SANFELICE, 2010; FERMINO et al. 2017).

Às vezes você está jogando e ninguém sabe, [...] 0 repórter não sabe nem o seu nome. No futebol, você sabe todas as posições, nome de jogadores, porque todo dia se transmite um treinamento, alguma reportagem (P3).

Então, peca um pouco pela diversificação e crítica. Hoje, não tem uma crítica dentro do futsal. Eu digo crítica no sentido assim: a equipe vai mal? Tudo bem. Eles vão na hora do jogo, os narradores de rádio geralmente, que estão mais envolvidos $e$ questionam, argumentam, fazem esse debate [...]. 0 torcedor dificilmente vai para um bar tomar o chope dele e discutir futsal. Não discute. Discute futebol e outras coisas mais [...]. Falta diversificação e a crítica no sentido de debate, de questionar o futsal [...]. Você vê comentaristas específicos e dezenas de abordagens no futebol, e a gente não tem isso no futsal [...]. Um programa para o torcedor ficar sabendo o que está acontecendo (P9).

No subcampo midiático-esportivo, esportes com menor capital simbólico (menor potencial para elevação dos níveis de audiência (BOURDIEU, 1997) acabam recebendo um tratamento superficial, mais voltado à divulgação de resultados do que à aproximação do público com o esporte e seus agentes (MARQUES et al., 2014; MARQUES et al., 2015).

A ampla e diversificada difusão de informações pelos meios de comunicação, própria da era da globalização, possibilita uma maior exposição dos atletas, que passam a ser mais reconhecidos pelo grande público (CAVALCANTI; CAPRARO, 2013). Neste processo, a inculcação de uma imagem positiva do atleta valoriza seus feitos, atrelando-o à posição de ídolo (COAKLEY, 2017), normalmente mais relacionada no esporte à perspectiva do herói (diferente dos campos da música ou dramaturgia) (HELAL, 2003; SANFELICE, 2010), e à exploração comercial agregada a ela.

Isso não somente confere valor simbólico e econômico às carreiras, como também aumenta o interesse do público (ROWE; GILMOUR, 2016), reforçando a lógica de reprodução dos meios de distribuição e acúmulo de capitais (BOURDIEU, 1993; 2013).

Ídolos atuam e operam em diferentes esferas da atividade humana contemporânea (artes, esportes, ciência, comércio, entre outras), influenciando os modos de ação das pessoas que os admiram (RYCHTECKY, 2013). Mesmo sendo parte de equipes em um esporte coletivo (no caso deste trabalho sobre futsal), atletas mais famosos e com vínculo afetivo mais próximo ao público poderiam influenciar positivamente a comercialização do esporte (LYNCH; ADAIR; JONSON, 2014) e, consequentemente, sua participação no espaço midiático-esportivo. P6 reforça esta perspectiva, ao abordar o apelo midiático e mercadológico de Falcão (considerado por muitos como o melhor jogador de futsal da história, e eleito por quatro vezes o melhor jogador de futsal do mundo) e a possibilidade de explorar sua imagem para atrair atenção para o futsal:

Sei lá, muitos dizem que se for comparar, tem até medo do nosso futsal terminar [após a aposentadoria de Falcão], pela [falta de] exposição. Porque o Falcão atrai muita mídia. O Falcão chama tudo, patrocínio. Então eu acho que [o futsal como um todo] deveria ser muito mais valorizado (P6). 
A percepção positiva sobre o desempenho de atletas depende de sua exposição e da importância construída sobre sua imagem (HAHN; CUMMMINS, 2017). A ausência de uma cobertura midiática que facilite a criação de ídolos é uma desvantagem de ordem comercial no subcampo midiático-esportivo, visto sua condição de alavancar lucros tanto das equipes quanto das ligas e associações (ZYVANOVICH et al., 2015), além da própria carreira profissional dos atletas (LYNCH; ADAIR; JONSON, 2014).

Bourdieu (1997) sugere que a mídia jornalística, incluindo a esportiva, pratica uma lógica de seleção de objetos e notícias que respeita o princípio da satisfação da necessidade de elevação dos índices de audiência. A notícia seria boa, nesta perspectiva, e desconsiderando seu valor de utilidade pública, apenas quando apresenta potencial para ser vendida ou atrair patrocinadores. Assim, acaba-se criando uma lógica de reprodução da ordem social (BOURDIEU, 2013) dentro do subcampo midiático-esportivo, na qual modalidades esportivas com maior potencial para gerar audiência acabam recebendo maior atenção, não apenas na transmissão de eventos, como também em informações suplementares que favoreçam seu consumo pelo público, atraindo novos patrocinadores e influenciando o modo como os espectadores incorporam o esporte em suas vidas (COAKLEY, 2017). Fica dificultada, como neste cenário descrito sobre o futsal brasileiro, a criação de um público apreciador, pois eles não conhecem suas especificidades e particularidades (BOURDIEU; DAUNCEY; HARE, 1998).

Uma das dificuldades apontadas pelos jogadores para uma melhor cobertura midiática sobre o futsal é a hegemonia do futebol no subcampo midiático-esportivo.

A mídia hoje divulga somente futebol. Então, apenas o que sobra de espaço nas grades das programações é colocado para outras modalidades, como basquete, vôlei, handebol e futsal (P9).

Daí o pessoal, um jogador lá, qualquer coisa, [futebol de] campo. Eles falam uma hora do [futebol de] campo. Só futebol de campo, e dois minutos de futsal (P6).

Este fenômeno de hegemonia do futebol no campo midiático-esportivo já é bem relatado pela literatura no Brasil e no exterior (BRÜGGEMANN; PIRES, 2012; GASTALDO, 2009; PACHECO BARRIO, 2012; MARQUES et al., 2015). O que é destacável neste cenário, é que o futsal, diferentemente de outros esportes, é um herdeiro cultural do futebol, compartilhando de certa bagagem cultural própria deste esporte (MASCARIN; OLIVEIRA; MARQUES, 2017), o que poderia funcionar como uma forma de maior atração do público e até de maior interesse dos veículos de comunicação. Mas os dados deste estudo sugerem que isso não ocorre exatamente deste modo.

Há uma reprodução, no campo esportivo, da lógica econômica de demanda e consumo (BOURDIEU, 1993). Normalmente, como é o grupo dominante (neste caso o futebol) quem estabelece os parâmetros do valor e poder simbólico, é a demanda produzida por ele que direciona quais são os objetos legítimos de valorização. Isso leva à determinação do que seriam produtos bons e ruins (doxa) (BOURDIEU, 1998a). Essa hierarquia dos bens é o que orienta os investimentos pelas oportunidades de lucro material e simbólico (BOURDIEU, 1998b).

Neste cenário de hegemonia do futebol, a maior atenção da mídia a esse esporte se justifica pela garantia de melhores índices de audiência, o que cria consumidores apenas conhecedores do modo ortodoxo de cobertura midiática do esporte, pois quem já conhece futebol e o consome acaba tendo acesso a informações sobre ele em maior abundância e 
facilidade, reforçando seus índices de audiência e o interesse da mídia em divulgá-lo. Betti (2001) denomina esse fenômeno de monocultura esportiva.

Embora tenha crescido nas últimas décadas a influência das mídias digitais sobre os modos de acesso e consumo do discurso midiático-esportivo (DAVID; MILLWARD, 2018; SANTOS; PIRES, 2016; WENNER, 2018), é possível perceber uma maior valorização, por parte dos atletas entrevistados, da cobertura midiática da televisão, relegando a um segundo plano o rádio, as home pages, as redes sociais e as mídias impressas.

Tal posicionamento dos jogadores pode ser considerado uma posição mais conservadora sobre as possibilidades de interação e divulgação midiática, reforçando certa hegemonia da televisão sobre a formação de opinião e divulgação de conteúdos sobre o esporte.

$\mathrm{Na}$ época das entrevistas (entre 2014 e 2016), de fato a televisão detinha certo monopólio sobre as transmissões de jogos de futsal, com a cobertura de partidas da LNF semanalmente em uma emissora de televisão por assinatura no Brasil, além de algumas transmissões esporádicas de campeonatos estaduais. Porém, a partir de 2018, fez-se mais comum a transmissão de jogos em tempo real por meio do Facebook e de sites destinados a esse fim, tanto por iniciativa dos próprios clubes (TV MARRECO FUTSAL, 2018), quanto da LNF (LNFTV, 2018), o que sugere certa ampliação no alcance das transmissões a espectadores que talvez não tivessem esse acesso anteriormente, representando, por parte destes agentes do subcampo do futsal, um movimento heterodoxo e de rompimento com a lógica hegemônica da televisão.

Em relação à transmissão televisiva, por um lado, os jogadores descrevem essa exposição midiática como positiva, mas, por outro, se incomodam com certo monopólio sobre os jogos transmitidos e informações aos espectadores.

Hoje, o futsal é transmitido apenas pela SporTV. Quando tinha a ESPN junto, tinha concorrência [...]. "Se eu não gosto desse tipo de mídia, vou para outro" (P9).

Eu torço para que cada vez mais isso [cobertura sobre o futsal] aumente nas emissoras de televisão, outras emissoras poderem transmitir os nossos jogos na TV, não só um canal. Tomara que isso melhore (P8).

Os jogadores demonstraram grande valorização da transmissão do futsal por emissoras abertas de televisão. Alguns atletas reclamaram que jogos de futsal em tais meios vêm diminuindo em quantidade nos últimos anos:

Em anos anteriores, jogos da seleção nacional passavam direto [em emissoras de televisão aberta] [...]. Mas, hoje, são apenas dois ou três jogos por ano (P15).

O monopólio de transmissões de eventos esportivos, através dos direitos de transmissão em emissoras por assinatura, é um fenômeno cada vez mais comum na mídia esportiva mundial, especialmente na Europa, pois se caracterizam como uma forma alternativa de arrecadação (SMITH; EVENS; IOSIFIDIS, 2016). Porém, a preocupação dos jogadores sobre esse cenário no Brasil justifica-se e legitima-se, pois apenas $29,5 \%$ dos lares brasileiros têm acesso às emissoras de televisão por assinatura, com adesão vinculada a condições socioeconômicas mais favorecidas (VALOR ECONÔMICO, 2015).

Percebe-se que, enquanto os jogadores almejam uma divulgação do esporte entre grupos de diversas posições na estrutura social brasileira, ampliando seu consumo, a quase exclusividade de transmissões em emissoras por assinatura reforça uma lógica de distinção, 
fazendo do futsal um produto menos consumido e, por isso, com códigos e particularidades compreendidos por poucos (BOURDIEU, 2013). Isso poderia ser interessante se os agentes envolvidos com o futsal desejassem alcançar um público distintivo, mas não parece ser o caso. Além disso, mesmo nas grades de programação de emissoras por assinatura, o futsal ainda concorre com o futebol, o que torna ainda mais desvantajosa essa unicidade de meios de divulgação televisiva.

Segundo alguns jogadores, o rádio, um veículo midiático de acesso aberto, consiste em importante meio de transmissão de jogos e notícias sobre futsal no Brasil, alternativo à televisão. Embora muitas emissoras de rádio transmitam sua programação por meio da internet, os atletas consideram este meio de divulgação midiática mais atuante principalmente em esfera regional, com transmissões voltadas principalmente ao público residente próximo às cidades-sede de equipes.

Geralmente são as rádios quem acompanham os clubes das cidades [menores]. Os jogos são transmitidos pelo rádio (P8).

A maioria das equipes da Liga [LNF] tem transmissão de jogos por rádio para suas cidades [...] meu pai e minha mãe escutam todos os jogos. Independente de televisão ou não. Pelo computador, [eles] 'puxam' na rádio (P7).

Tal fenômeno de atuação dos meios radiofônicos também acontece com o futebol em outros países, como o Reino Unido (DAUNCEY; HARE, 2014). Embora seja um veículo de comunicação tradicional e pioneiro na transmissão de algumas formas de manifestação do esporte (PACHECO BARRIO, 2012), o rádio se coloca como uma mídia heterodoxa neste universo. Consiste em uma forma alternativa à hegemonia da televisão sobre a mídia esportiva (SHERWOOD; NICHOLSON; MARJORIEBANKS, 2017), ao divulgar jogos e notícias sobre conteúdos específicos relativos ao futsal, a um público mais diversificado.

\subsection{REFLEXÕES PARA A MELHORIA DA COBERTURA MIDIÁTICA SOBRE O FUTSAL: HABITUS DOS JOGADORES E ESTRATÉGIAS PARA ACÚMULO DE CAPITAIS.}

É possível apontar que faz parte do habitus dos entrevistados não apenas a dedicação aos treinamentos e competições, mas também a atenção à divulgação do próprio trabalho e preocupação em garantir meios de acumularem capitais simbólico-esportivo e econômico. Inclusive, com posições críticas a respeito disso. Tal cenário se justifica pelas condições de trabalho e possibilidades de desenvolvimento de carreira estar estreitamente relacionadas à cobertura midiática.

Em um jogo transmitido pela televisão, o 'moleque' faz uma defesa bonita. Aí o comentarista fala, 'Esse goleiro tem só 20 anos, tem chance de jogar na Seleção' [...]. É mais fácil aparecer, influencia a imagem do jogador (P19).

[...] a Liga [LNF] é vendida, a emissora compra o direito de imagem, aí entra aqui, coloca uma câmera dentro do ginásio e passa o jogo. [...] faz um 'Big Brother' na sua casa, você deixa? Você não ganha um real (P1).

P19 ressalta o potencial da mídia em influenciar as opiniões dos espectadores sobre o conteúdo exibido. Segundo Bourdieu (1997, p.28), isso "[...] implica sempre uma construção social da realidade capaz de exercer efeitos sociais de mobilização (ou de desmobilização)". Neste processo, percebe-se o potencial da mídia em oferecer capital simbólico-esportivo aos 
atletas (e também retirá-lo), a partir do modo como seus desempenhos e participações esportivas são expostos e comentados (MARQUES et al., 2015), o que, direta ou indiretamente, influencia o acesso e acúmulo de capital econômico (COAKLEY, 2017) através da carreira esportiva.

Ainda na seara da preocupação com meios de acúmulo de capitais, especialmente os econômicos, considerando que o esporte é um dos melhores meios de exposição de marcas e produtos no século XXI (ROWE; GILMOUR, 2010), que a televisão é o veículo mais popular de divulgação de eventos esportivos (SMITH; EVENS; IOSIFIDIS, 2016), que tem certo monopólio sobre a formação ideológica de grande parcela da população (BOURDIEU, 1997), e que há um grande interesse de investidores em aproximar-se do público (HOWE, 2004), inserções na programação televisiva aberta poderiam, até certa medida, contribuir para o crescimento do número de espectadores e do consumo do futsal como produto, talvez potencializando as possibilidades de ganhos e de carreira profissional bem sucedida aos jogadores.

Em sincronia com tal perspectiva, alguns atletas sugerem que a cobertura televisiva seria a principal maneira de atrair investidores ao futsal, assim como ampliar o número de seus espectadores e consumidores.

O que chama patrocinador chama dinheiro. É fundamental estar na televisão. [Patrocínio em] Camisa, placa no ginásio, tudo depende da televisão (P15).

O futsal tinha que estar em qualquer canal [emissora de televisão] aberto. Isso atrairia mais recurso financeiro, divulgar mais o esporte (P16).

Assim, alguns entrevistados reivindicam uma ação mais efetiva dos clubes para aproximarem-se dos veículos midiáticos. Há sugestões como a contratação de assessores de imprensa, apontamentos sobre fatos ocorridos na rotina das equipes e infraestrutura mais adequada para transmissão de jogos pela televisão.

Que tipo de trabalho os clubes fazem? Todos os clubes têm um assessor de imprensa efetivo que faz a divulgação [...] ou só acessam a rádio da cidade? (P9)

Já ouvi falar que a Globo queria transmitir a LNF, só que pediu melhores condições de trabalho. Pediu ginásios em boas condições [...] São apenas seis, sete ginásios de equipes da LNF que comportam uma transmissão televisiva de boa qualidade (P15).

Tal perspectiva pode ser interpretada como um traço ortodoxo do habitus dos atletas em relação à dominação da mídia sobre os conteúdos veiculados, além do fortalecimento de uma perspectiva hegemônica da televisão sobre a formação de opinião do público, legitimando esta condição. $O$ mesmo acontece em outros esportes, como ações de adaptação bem-sucedidas de clubes e dirigentes às demandas da mídia, como o Comitê Paralímpico Brasileiro, que subsidiou a atuação de jornalistas do país em edições de Jogos Paralímpicos (MARQUES et al., 2014), e do voleibol, que promoveu adaptações de suas regras às demandas televisivas (MARCHI JUNIOR, 2004; PIRES, 2006).

Outra proposta dos jogadores para a melhoria da cobertura midiática sobre o futsal foi a vinculação das equipes de futsal a clubes de futebol profissional. Considerando a hegemonia do futebol na mídia e sua capacidade de gerar audiência e investimentos, esta seria uma estratégia, para atrair mais atenção de público e patrocinadores ao futsal, que talvez merecesse maiores discussões e aprofundamento para estímulo a implementações tanto em esfera privada, quanto pública. 
Se você transmitir um jogo do Corinthians na SportTV, a audiência vai ser maior, porque corintiano, não importa o esporte, vai acompanhar (P10).

Era pior quando era só Krona [equipe de futsal de Joinville/SC], mas agora que virou JEC [vinculação da Krona com o Joinville Esporte Clube, equipe de futebol profissional], bastante gente acompanha. Ninguém quer torcer por uma empresa, quer torcer por uma 'camisa' [de clube de futebol] (P6).

É inegável a hegemonia do futebol como principal produto da indústria midiáticaesportiva no Brasil (BETTI, 2001). Ao associar equipes de futsal às de futebol, expõe-se novamente o habitus ortodoxo dos jogadores, pois se rendem a uma posição secundarizada do futsal em relação ao futebol, e procuram associar seus nomes a grandes marcas (clubes de futebol) já estabelecidas nos campos esportivo e midiático, aumentando seu capital simbólico. Deste modo, na busca por acúmulo de capitais, tal posicionamento de submissão à hegemonia do futebol acaba por subjugar o futsal em relação a este esporte, reforçando uma posição de menor protagonismo no subcampo midiático-esportivo.

\section{CONSIDERAÇÕES FINAIS}

Este trabalho teve como objetivo investigar a perspectiva de jogadores brasileiros de elite de futsal masculino a respeito da cobertura midiática sobre este esporte no Brasil, com base em categorias sociológicas de Pierre Bourdieu. Tal referencial permitiu analisar a posição do futsal no subcampo midiático-esportivo e identificar traços dos habitus dos jogadores entrevistados.

Na perspectiva dos jogadores, o futsal ocupa uma posição desprestigiada no subcampo midiático-esportivo, com formas de divulgação que dificultam a atração de investimentos e 0 desenvolvimento de carreiras profissionais. É possível descrever o habitus dos jogadores como ortodoxo frente ao reconhecimento dessa posição desfavorável e adoção de estratégias que aceitam e legitimam a violência simbólica da televisão e a hegemonia do futebol. Embora se incomodem com esse exercício de poder de ambos, os atletas propõem ações de adaptação do futsal às normas impostas no subcampo, de modo que possam melhorar suas condições de trabalho e acumulação de capitais econômicos e simbólicos. Tal forma de ação pode reforçar uma posição de submissão do futsal neste espaço, não contribuindo necessariamente para a ampliação da cobertura midiática (além da televisão) e de maior valorização do futsal no campo midiático-esportivo (como um esporte com autonomia para geração de interesse e recursos).

Fica clara a maior valorização, por parte dos atletas, da televisão aberta como principal meio de divulgação do esporte. 0 que surpreende é a pequena valorização dada à internet como meio eficiente de divulgação do futsal.

Por fim, embora esse estudo tenha sido direcionado para o futsal brasileiro, fica 0 registro e convite para esse mesmo tipo de leitura e análise em outros esportes e contextos, que também estejam circunscritos a esse universo de dominação, no limite, simbólica. 


\section{REFERÊNCIAS}

ALTMANN, Helena; REIS, Heloísa Helena Baldy dos. Futsal feminino na América do Sul: trajetórias de enfrentamentos e de conquistas. Movimento, v.19, n.3, p. 211-232, 2013.

BERDEJO DEL FRESNO, Daniel. A review about futsal. American Journal of Sports Medicine, v.2, n.3, p.70, 2014.

BETTI, Mauro. Esporte na mídia ou esporte da mídia. Motrivivência, v.17, p.1-3, 2001.

BOURDIEU, Pierre. The forms of capital. In: Richardson E. (ed.) Handbook of Theory of Research for the Sociology of Education. Greenword, 1986. p.241-258.

BOURDIEU, Pierre. Program for a sociology of sport. Sociology of Sport Journal, v.5, n.2, p.153-161, 1988.

BOURDIEU, Pierre. O poder simbólico. Rio de Janeiro: Bertrand Brasil, 1989.

BOURDIEU, Pierre. Sociology in question. London: Sage 1993.

BOURDIEU, Pierre. Sobre a televisão. Rio de Janeiro: Zahar, 1997.

BOURDIEU, Pierre. Practical reasons: about the theory of action. Stanford: Stanford University, 1998a.

BOURDIEU, Pierre. Método científico e hierarquia social dos objetos. In: NOGUEIRA, Maria Alice; CATANI, Afrânio Mendes (Orgs.). Escritos de Educação. Petrópolis: Vozes, 1998b. p. 33-38.

BOURDIEU, Pierre. A distinção: Crítica social do julgamento. Porto Alegre: Zouk, 2013.

BOURDIEU, Pierre; DAUNCEY, Hugh; HARE, Geoff. The state, economics and sport. Culture, Sports, Society, v.1, n.2, p.15-21, 1998.

BOURDIEU, Pierre; WACQUANT, Loic. An invitation to reflexive sociology. Chicago: University of Chicago, 1992.

BRAUN, Virginia; CLARKE, Victoria. Using thematic analysis in psychology. Qualitative research in Psychology, v.3, n.2, p.77-101, 2006.

BRÜGGEMANN, Angelo Luis; PIRES, Giovani de Lorenzi. Uma nova imagem/ identidade para a seleção brasileira de futebol: estudo a partir da mídia. In: CONGRESSO SULBRASILEIRO DE CIÊNCIAS DO ESPORTE. Anais... .Rio Grande: CBCE, 2017. p.1-14.

CAREGNATO, André Felipe et al. A produção científica sobre futsal: análise de dissertações e teses publicadas no portal da Capes entre 1996-2012. Motrivivência, v.27, n.4, p.15-34, 2015.

CAVALCANTI, Everton de Albuquerque; CAPRARO, André Mendes. A mídia e o ídolo Ronaldo: analisando as matérias da Folha online (2002-2009) Revista Brasileira de Ciências do Esporte, v.35, n.3, p.741-755, 2013.

COAKLEY, Jay. Sports in society: issues and controversies. 12 ed. New York: McGraw-Hill, 2017. 
CUSHION, Christopher; KITCHEN, Will. Pierre Bourdieu: a theory of (coaching) practice. In: JONES, Robyn; POTRAC, Paul; CUSHION, Christian; RONGLAN, Lars Tore (eds.). The sociology of sport coaching. Oxon: Routledge, 2011, p.40-53.

DAUNCEY, Hugh; HARE, Geoff. Sport and media: representing and conceptualising identity and community. Movement \& Sport Sciences - Science \& Motricité, v.86, p. 5-14, 2014.

DAVID, Matthew; MILLWARD, Peter. Sport and new media. In: GIULIANOTTI, Richard. Routledge handbook of the Sociology of Sport. Nova York: Routledge, 2018. p.377-388-397.

FERMINO, Antonio Luis et al. Futebol Masculino nos Jogos olímpicos de Londres/2012: enquadramentos de alguns telejornais brasileiros. Lúdica Pedagógica. v.25, n.1, p.117-126, 2017.

GASTALDO, Edson. "O país do futebol" mediatizado: mídia e Copa do Mundo no Brasil. Sociologias, v.11, n.22, p.352-369, 2009.

GIULIANOTTI, Richard. Sport: a critical sociology. Bodmin: MPG Book, 2005.

HAHN, Dustin A.; CUMMINS, R. Glenn. Differentiating objective sport knowledge versus subjective sport fanship via a test of exemplification in sport media. Communication and sport,v, p.1-18, 2017.

HELAL, Ronaldo. A construção de narrativas de idolatria no futebol brasileiro. Alceu, v.4, n.7, p.19-36, 2003.

HESMONDHALGH, David. Bourdieu, the media and cultural production. Media, Culture \& Society, v.28, n.2, p.211-231, 2006.

HOWE, David. Sport, professionalism and pain: ethnographies of injury and risk. New York: Routledge, 2004.

LNF. Equipes. Disponível em: < http://ligafutsal.com.br/>. Acesso em: 30 maio 2017.

LNF. Equipes. Disponível em: < http://ligafutsal.com.br/>. Acesso em: 08 out 2018.

LNFTV. Jogos ao vivo. Disponível em: <https://tv.ligafutsal.com.br/>. Acesso em: 04 out. 2018.

LYNCH, Sandra; ADAIR, Daryl; JONSON, Paul. Professional athletes and their duty to be role models. Research in Ethical Issues in Organizations, v.12, p. 75-90, 2014.

MARCHI JUNIOR, Wanderley. Sacando o voleibol. Hucitec: Unijuí, 2004.

MARCHI JUNIOR, Wanderley. O esporte "em cena": perspectivas históricas e interpretações conceituais para a construção de um modelo analítico. The Journal of the Latin American Socio-cultural Studies of Sport, v.5, n.1, p. 46-67, 2015.

MARQUES, Renato Francisco Rodrigues. Contribuições da Obra de Pierre Bourdieu para a Pesquisa em Sociologia do Esporte no Século XXI. In: ALMEIDA, Marco Antonio Bettine de (Org.). Estudos interdisciplinares em sociologia do esporte. São Paulo: Escola de Artes, Ciências e Humanidades, 2015a. p. 9-37.

MARQUES, Renato Francisco Rodrigues. O conceito de esporte como fenômeno globalizado: pluralidade e controvérsias. Revista Observatorio del Deporte, v. 01, n. 01, p. 147-185, 2015b. 
MARQUES, Renato Francisco Rodrigues; GUTIERREZ, Gustavo Luis. O esporte paralímpico no Brasil: profissionalismo, administração e classificação de atletas. São Paulo: Phorte, 2014.

MARQUES, Renato Francisco Rodrigues; MARCHI JUNIOR, Wanderley. O futsal brasileiro após a mudança na gestão da CBFS: transformação da estrutura social e do habitus esportivo. In: CONGRESO LATINOAMERICANO DE SOCIOLOGIA. Anais ...., Montevideo: ALAS, 2017. p.11.

MARQUES, Renato Francisco Rodrigues et al. El árbitro de fútbol sala como agente pedagógico en las clases infantiles. ¿Fiscal o educador? Des-encuentros, v.10, p.18-28, 2013.

MARQUES, Renato Francisco Rodrigues et al. A cobertura midiática sobre o esporte paralímpico: o ponto de vista de atletas brasileiros. Movimento, v.20, n.3, p. 989-1015, 2014.

MARQUES, Renato Francisco Rodrigues et al. A cobertura mediática sobre o desporto paralímpico: perspetivas de atletas portugueses. Motricidade, v.11, p.123-147, 2015.

MASCARIN, Rafaela Bevilacqua; OLIVEIRA, Flávia Volta Cortez; MARQUES, Renato Francisco Rodrigues. Feminilidade e Preconceito de Gênero no Futsal: uma perspectiva de atletas brasileiras. Fluxos \& Riscos, v.2, n.2, p.83-96, 2017.

MINISTÉRIO DO ESPORTE. Diesporte. 2015. Disponível em: <http://www.esporte.gov.br/ diesporte/>. Acesso em: 10 set. 2016.

MOORE, Richard et al. A systematic review of futsal literature. American Journal of Sports Science and Medicine, v.2, n.3, p.108-116, 2014.

PACHECO BARRIO, Manuel Antonio. Los programas deportivos radiofónicos en la medianoche: La supremacía del fútbol en los contenidos. Historia y Comunicación Social, v.17, p. 269-295, 2012.

PIRES, Giovani de Lorenzi. Mídia, esporte e ilusão. In: FÓRUM INTERNACIONAL DE ESPORTE E LAZER. Rio de Janeiro: SESC 2006. p.1-11.

ROWE, David; GILMOUR, Callum. Sport, media, and consumption in Asia: a merchandised milieu. American Behavioral Scientist, v.53, n.10, p. 1530-1548, 2010.

RYCHTECKY, Antonin. Are olympians real idols of young people for their motivation and participation in sport? Kinanthropologica, v.49, n.1, p. 65-76, 2013.

SANFELICE, Gustavo Roese. Campo midiático e campo esportivo: suas relações e construções simbólicas. Revista Brasileira de Ciências do Esporte, v.31, n.2, p.137-153, 2010.

SANTANA, Wilton Carlos; RIBEIRO, Danilo Augusto. Idades de início de atletas de futsal de alto rendimento na prática sistemática e em competições federadas da modalidade. Pensar a Prática, v.13, n.2, p.1-17, 2010.

SANTOS, Silvan Menezes; PIRES, Giovani de Lorenzi. Manifestações sociais e mídia na Copa das Confederações 2013: estudo com professores de Educação Física em formação inicial. Movimento, v.22, n.1, p. 199-201, 2016.

SHERWOOD, Merryn; NICHOLSON, Mathew; MARJORIBANKS, Tim. Access, agenda building and information subsidies: media relations in professional sport. International Review for the Sociology of Sport. v.52, n.8, p.992-1007, 2017. 
SMITH, Paul; EVENS, Tom; IOSIFIDIS, Petros. The next big match: convergence, competition and sports media rights. European Journal of Communication, v.31, n.5, p. 536-550, 2016.

TV MARRECO FUTSAL. Jogos ao vivo. Disponível em: https://www.facebook.com/ cresolmarrecol. Acesso em: 04 out. 2018.

VALOR ECONÔMICO. IBGE: TV por assinatura chega a quase um terço dos domicílios no país. 2015. Disponível em: < http://www.valor.com.br/brasil/4027358/ibgetv-por-assinatura-chega-quase-um-terco-dos-domicilios-no-pais>. Acesso em: 28 junho 2017.

VIGARELLO, Georges. Sistemas de esporte, esportes concorrentes. In: ENCREVÉ, Pierre; LAGRAVE, Rose-Marie. (Orgs.) Trabalhar com Bourdieu. Rio de Janeiro: Bertrand Brasil, 2005. p.185-196.

VOSER, Rogério da Cunha; GIUSTI, João Gilberto. 0 futsal e a escola: uma perspectiva pedagógica. 2. ed. Porto Alegre: Penso, 2015.

WENNER, Lawrence, A. Sport and media. In: GIULIANOTTI, Richard. Routledge handbook of the Sociology of Sport. Nova York: Routledge, 2018. p.377-387.

ZYVANOVICH, Nenad et al. Sports, sports idols and idolatry. Journal of Sports Science, v.3 p.309-316, 2015. 